\title{
Antioxidant Capacities and Total Phenolic Contents Enhancement with Acute Gamma Irradiation in Curcuma alismatifolia (Zingiberaceae) Leaves
}

\author{
Sima Taheri ${ }^{1{ }^{*},}$, Thohirah Lee Abdullah ${ }^{1}{ }^{1}$, , Ehsan Karimi ${ }^{1,4}$, Ehsan Oskoueian ${ }^{2,4}$ and \\ Mahdi Ebrahimi ${ }^{3}$
}

1 Department of Crop Science, Faculty of Agriculture, Universiti Putra Malaysia, 43400 Serdang, Selangor, Malaysia; E-Mail: ehsan_b_karimi@yahoo.com

2 Institute of Tropical Agriculture, Universiti Putra Malaysia, 43400 Serdang, Selangor, Malaysia; E-Mail: ehs424@yahoo.com

3 Department of Veterinary Preclinical Sciences, Faculty of Veterinary Medicine, Universiti Putra Malaysia, 43400 Serdang, Selangor, Malaysia; E-Mail: mehdiebrahimii@gmail.com

4 Agriculture Biotechnology Research Institute of Iran (ABRII)-East and North-East Branch, P.O.B. 91735/844 Mashhad, Iran

* Authors to whom correspondence should be addressed;

E-Mails: Sima.taheri@mutiara.upm.edu.my (S.T.); thohirah@upm.edu.my (T.L.A.);

Tel.: +6-01-2372-3585 (S.T. \& T.L.A.); Fax: +6-03-8943-5973 (S.T. \& T.L.A.).

Received: 28 May 2014; in revised form: 24 June 2014 / Accepted: 7 July 2014 /

Published: 23 July 2014

\begin{abstract}
The present study was conducted in order to assess the effect of various doses of acute gamma irradiation $(0,10,15$, and $20 \mathrm{~Gy})$ on the improvement of bioactive compounds and their antioxidant properties of Curcuma alismatifolia var. Sweet pink. The high performance liquid chromatography (HPLC) and gas chromatography (GC) analysis uncovered that various types of phenolic, flavonoid compounds, and fatty acids gradually altered in response to radiation doses. On the other hand, antioxidant activities determined by 1,1-Diphenyl-2-picryl-hydrazyl (DPPH), ferric reduction, antioxidant power (FRAP), and 2,2-azino-bis-3-ethylbenzothiazoline-6-sulfonic acid (ABTS) radical scavenging assay showed a higher irradiation level significantly increased the antioxidant properties. This study revealed an efficient effect of varying levels of gamma radiation, based on the pharmaceutical demand to enhance the accumulation and distribution of bioactive compounds such as phenolic and flavonoid compounds, fatty acids, as well as their antioxidant activities in the leaves of C. alismatifolia var. Sweet pink.
\end{abstract}


Keywords: antioxidant activity; bioactive compounds; Curcuma alismatifoli; gamma irradiation

\section{Introduction}

Bioactive compounds often accumulate in the plant in small quantities and sometimes in specific cells [1]. Among them some are known as phenolic, flavonoids, and essential oils, which possess a wide range of biological activities such as antioxidant, anti-inflammatory, anti-aging, anti-bacterial, anti-tumor, and other functions $[2,3]$.

Flavonoids and phenolic acids are the most important groups of secondary metabolites in plants that consider as good sources of natural antioxidants in human diets [4]. These compounds are able to scavenge free superoxide radicals, reduce the risk of cancer, and protect biological systems against the deleterious effects of oxidative incidents on macromolecules, such as lipids, proteins, carbohydrates, and DNA. Based on previous studies flavonoids and phenolic acids were introduced as an antioxidant $[5,6]$.

Antioxidants are compounds known to slow or delay lipid oxidation. Suppressive antioxidants can separate free radicals or single oxygen before any significant oxidant occurrence. However, chain-breaking antioxidants delay or slow the oxidative processes after they start up [7,8].

Consumer demand for healthier products containing less synthetic additives is driving research efforts to seek out alternative sources of natural antioxidants. Phenolic and flavonoid compounds are natural antioxidant that found in plants and they are attracting a great deal of attention due to increasing evidence suggesting that they may prevent chronic conditions, such as cancer, atherosclerosis, and neurological diseases [9].

The genus Curcuma from Zingiberaceae family originated from the Indo-Malayan Region [10] with a wide-spread distribution in the tropics of Asia to Africa and Australia.

C. alismatifolia is a monocotyledonous perennial, originating from tropical and subtropical areas of Northern Thailand and Cambodia [11].

One of the most challenging pursuits in the realm of pharmaceutical and medical sciences is to investigate for latest and more potent drugs with fewer toxic effects and completely reversible. Much of these features can easily find from the natural compounds of plants [12]. Several years, gamma irradiation has been considered as a rapid and new method to enhance the qualitative and quantitative characters of many plants. Gamma irradiation has been widely used in biology and medicine in terms of biological effects of low dose stimulation to high-dose inhibition [13]. Several studies have shown that relatively low-doses ionizing irradiation on photosynthetic microorganisms and plants accelerated cell growth, cell proliferation, germination rate, enzyme activity, crop yields, as well as stress resistance [14]. Therefore, this experiment was conducted to analyze the bioactive compounds, such as phenolic, flavonoid, and fatty acids, using HPLC and GC, respectively. Furthermore, their antioxidant activities were evaluated under different treatment of the acute gamma irradiation in the leaves of C. alismatifolia var. sweet pink. 


\section{Results and Discussion}

\subsection{Total Phenolics (TP) and Flavonoids (TF) Content}

The results indicated that the accumulation of TP and TF in the plant leaves was considerably affected by different levels of acute gamma irradiation and it had a significant $(p<0.05)$ effect on TP and TF of irradiated groups (Table 1). The overall results demonstrated that leaves under 20 Gy of acute gamma irradiation exhibited higher content of TP and TF with values of $3.15 \pm 1.73$ (GAE)/g DW and $2.87 \pm 0.31 \mathrm{rutin} / \mathrm{g}$ DW compared to Control with respective values of $2.08 \pm 0.12(\mathrm{GAE}) / \mathrm{g} \mathrm{DW}$ and $1.61 \pm 0.48 \mathrm{rutin} / \mathrm{g} \mathrm{DW}$, respectively. Previous studies demonstrated that various forms of irradiation influenced the phenolics and flavonoids content. Gamma irradiation (10 KGy) increased phenolic acid content in cinnamon and clove while phenolic content in nutmeg did not change $[15,16]$. Variyar et al. [16] indicated that the free phenolic (aglycone) content of the soybean samples treated with gamma irradiation at levels ranging from 0.5 to $5 \mathrm{kGy}$ increased. The increment of TP and TF content under different levels of gamma irradiation could be ascribed to the release of these compounds from glycosidic forms and the degradation of larger compounds into smaller ones by gamma irradiation [17].

Table 1. Total phenolics and flavonoids content in the leaves of $C$. alismatifolia var. sweet pink under different dose levels of acute gamma irradiation (Mean $\pm \mathrm{SEM} ; n=3$ ).

\begin{tabular}{ccc}
\hline Dose & Phenolic Content $^{{ }^{1}}$ & Flavonoid Content $^{\mathbf{2}^{2}}$ \\
\hline Control & $2.08 \pm 0.12^{\mathrm{a}}$ & $1.61 \pm 0.48^{\mathrm{a}}$ \\
$10(\mathrm{~Gy})$ & $2.11 \pm 1.25^{\mathrm{a}}$ & $1.88 \pm 1.82^{\mathrm{a}}$ \\
$15(\mathrm{~Gy})$ & $2.76 \pm 0.32^{\mathrm{b}}$ & $2.09 \pm 0.57^{\mathrm{b}}$ \\
$20(\mathrm{~Gy})$ & $3.15 \pm 1.73^{\mathrm{c}}$ & $2.87 \pm 0.31^{\mathrm{c}}$ \\
\hline
\end{tabular}

${ }^{1} \mathrm{mg}$ gallic acid equivalent/g DW; ${ }^{2} \mathrm{mg}$ rutin equivalent/g DW; ${ }^{\text {a,b,c }}$ Means with the same letter between different columns are not significantly different at $p<0.05$.

\subsection{Profiling of Phenolic and Flavonoid Compounds Using HPLC}

HPLC is currently the method of choice to accurately determine both the composition and the absolute concentration of the secondary metabolites of a sample [18]. The phenolic and flavonoid compounds were identified based on their conservation times and quantified according to respective standard calibration curves. The HPLC chromatogram revealed that cinnamic acid and rutin were the main phenolic and flavonoid compounds with values of $1015 \mu \mathrm{g} / \mathrm{g}$ DW and $1032.7 \mu \mathrm{g} / \mathrm{g}$ DW in the leaves of studied C. alismatifolia var. Sweet pink, respectively (Tables 2 and 3). It is apparent that phenolic and flavonoid accumulation and partitioning was considerably affected by differentlevels of acute gamma irradiation. Meanwhile, increasing dose levels of acute gamma irradiation from 5 to 20 Gy resulted in enhancement of various types of phenolic and flavonoid compounds (Tables 2 and 3 ). Previous researchers demonstrated that the phenolic acid content increased by gamma irradiation (10 kGy) treatment with cinnamon and clove while phenolic content in nutmeg did not change [15]. The HPLC chromatogram in Figure 1A,B shows the phenolic compounds in the leaves of C. alismatifolia var. Sweet Pink under different levels of acute gamma irradiation ( 0 and $20 \mathrm{~Gy}$ ) as an instance. 
Table 2. Concentration of different phenolic compounds in the leaves of $C$. alismatifolia var. sweet pink under different dose levels of acute gamma irradiation (Mean $\pm \mathrm{SEM} ; n=3$ ).

\begin{tabular}{ccccccccc}
\hline \multicolumn{7}{c}{ Phenolic Contents ( $\boldsymbol{\mu g} / \mathbf{g}$ Dry Sample) } \\
\hline Dose & Gallic Acid & Salicylic Acid & Caffeic Acid & Catechin & Epicatechin & Cinnamic Acid & Ellagic Acid & Resorcinol \\
\hline Control & ND & $406.2 \pm 37.72^{\mathrm{d}}$ & $125.2 \pm 7.663^{\mathrm{d}}$ & $212.9 \pm 15.61^{\mathrm{d}}$ & $856.4 \pm 57.05^{\mathrm{d}}$ & $1015.4 \pm 76.15^{\mathrm{d}}$ & $182.6 \pm 12.12^{\mathrm{d}}$ & $195.9 \pm 16.71^{\mathrm{d}}$ \\
10 (Gy) & ND & $595.5 \pm 51.43^{\mathrm{c}}$ & $181.6 \pm 9.12^{\mathrm{c}}$ & $231.2 \pm 17.04^{\mathrm{c}}$ & $795.2 \pm 45.32^{\mathrm{c}}$ & $1033.1 \pm 67.18^{\mathrm{c}}$ & $204.7 \pm 16.76^{\mathrm{c}}$ & $227.5 \pm 18.33^{\mathrm{c}}$ \\
15 (Gy) & ND & $688.1 \pm 56.11^{\mathrm{b}}$ & $203.7 \pm 15.01^{\mathrm{b}}$ & $255.6 \pm 21.12^{\mathrm{a}, \mathrm{b}}$ & $877.1 \pm 36.72^{\mathrm{b}}$ & $1052.7 \pm 56.26^{\mathrm{b}}$ & $235.1 \pm 18.27^{\mathrm{b}}$ & $253.5 \pm 21.22^{\mathrm{b}}$ \\
20 (Gy) & ND & $785.3 \pm 34.25^{\mathrm{a}}$ & $227.2 \pm 13.02^{\mathrm{a}}$ & $269.1 \pm 23.51^{\mathrm{a}}$ & $928.3 \pm 78.94^{\mathrm{a}}$ & $1081.5 \pm 89.35^{\mathrm{a}}$ & $269.3 \pm 21.03^{\mathrm{a}}$ & $282.1 \pm 23.67^{\mathrm{a}}$ \\
\hline
\end{tabular}
ND: not detected; a,b,c,d Means within columns with different superscript are significantly different at $p<0.05$.

Table 3. Concentration of different flavonoids compounds in the leaves of $C$. alismatifolia var. sweet pink under different dose levels of acute gamma irradiation (Mean $\pm \mathrm{SEM} ; n=3$ ).

\begin{tabular}{cccccc}
\hline \multicolumn{5}{c}{ Flavonoid Contents ( $\boldsymbol{\mu g} / \mathbf{g}$ Dry Sample) } \\
\hline Dose & Rutin & Naringin & Apigenin & Quercetin & Myricetin \\
\hline Control & $1032.7 \pm 67.05^{\mathrm{d}}$ & $271.5 \pm 17.01^{\mathrm{d}}$ & ND & $964.1 \pm 76.05^{\mathrm{d}}$ & $166.1 \pm 9.51^{\mathrm{d}}$ \\
10 (Gy) & $1286.5 \pm 89.03^{\mathrm{c}}$ & $355.1 \pm 21.01^{\mathrm{c}}$ & ND & $1025.8 \pm 86.07^{\mathrm{c}}$ & $225.6 \pm 14.42^{\mathrm{c}}$ \\
15 (Gy) & $1545.5 \pm 111.09^{\mathrm{b}}$ & $482.9 \pm 34.03^{\mathrm{b}}$ & ND & $1131.3 \pm 75.12^{\mathrm{b}}$ & $282.5 \pm 16.02^{\mathrm{b}}$ \\
20 (Gy) & $1704.7 \pm 123.05^{\mathrm{a}}$ & $564.1 \pm 43.05^{\mathrm{a}}$ & ND & $1292.4 \pm 91.05^{\mathrm{a}}$ & $351.1 \pm 21.02^{\mathrm{a}}$ \\
\hline
\end{tabular}

ND: not detected; a,b,c,d Means within columns with different superscript are significantly different at $p<0.05$. 
Figure 1. (A) The HPLC chromatogram of phenolic compounds in the non-treated leaves of $C$. alismatifolia var. sweet pink; (B) The HPLC chromatogram of phenolic compounds in the leaves of $C$. alismatifolia var. Sweet pink under 20 Gy acute gamma irradiation. Compound identification as labeled (concentration: $1 \mathrm{mg} / \mathrm{mL}$ ).
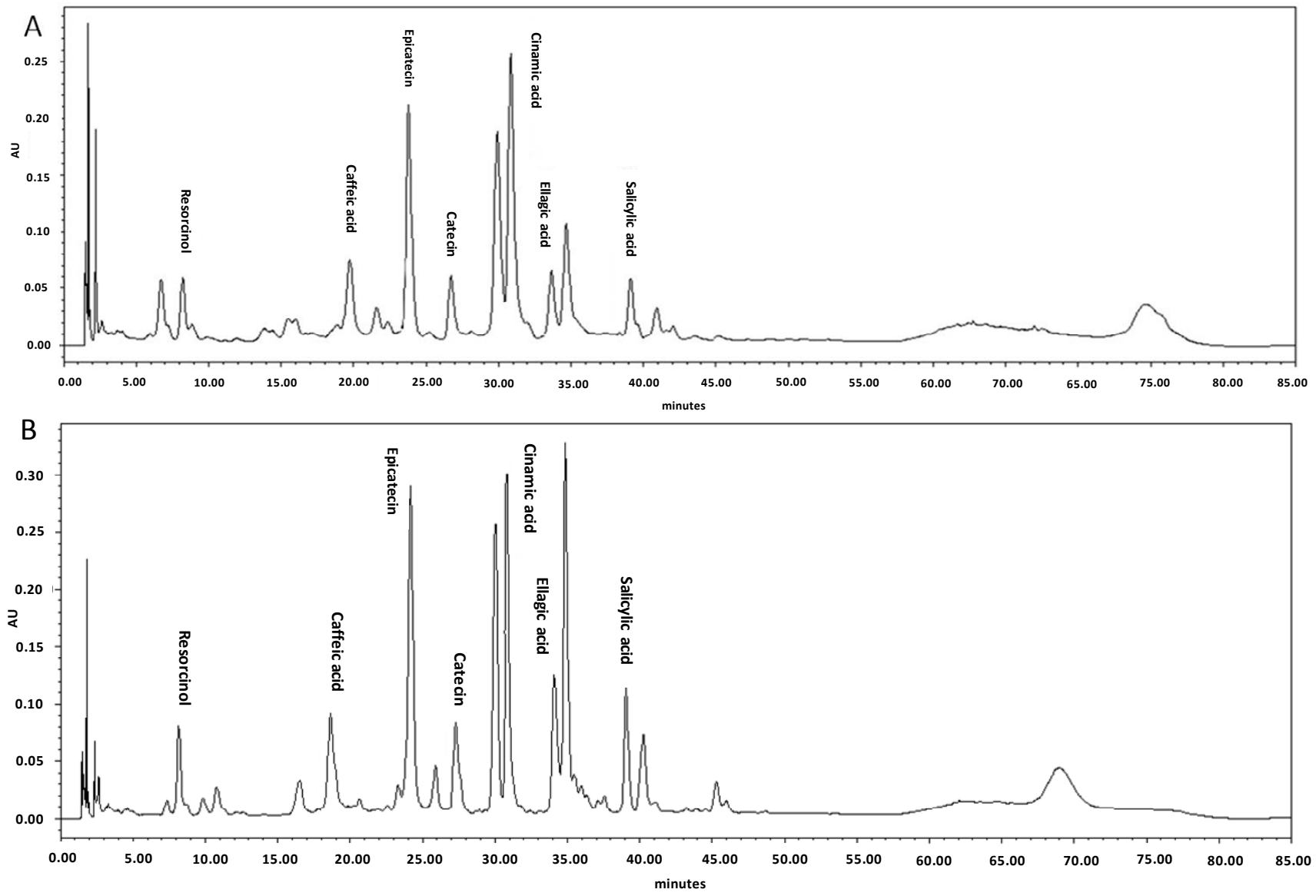

\subsection{Fatty Acid Composition of Irradiated Leaves}

The fatty acid composition of the $C$. alismatifolia leaves with different gamma irradiation treatment levels has been presented in Table 4 . The proportion of leaves fatty acids having 18 carbons was quite consistent across the four treatment levels, ranged from $49.29 \%$ to $58.15 \%$ (Table 4). Mean concentrations of C18:0, C18:1n-9, C18:2n-6, and C18:3n-3 were 5.22\%, 11.05\%, 16.59\%, and $20.76 \%$, respectively. On the other hand, C18:3n-3 increased in a linear manner with increasing the irradiation intensity. The different levels of irradiation showed significant $(p<0.05)$ effects on C18:3n-3 in the leaves. It has been reported that a number of intracellular constituents, including pigments [19], amino acids [20], and fatty acids [21], which could be responsible for radio-resistance. Byun et al. [22] reported non-significant changes in the fatty acid profile of soybean seeds with different intensity of gamma irradiation in contrast Štajner et al. [23] established that doses up to $10 \mathrm{kGy}$ caused insignificant changes in total lipids, fatty acid composition, peroxide value, and trans fatty acid content of soybean. The gamma irradiation for $C$. alismatifolia leaves showed a significant increase in omega- 3 fatty acid as the intensity of gamma irradiation increased. 
Table 4. Leaves Fatty acid composition of C. alismatifolia var. Sweet Pink under different dose levels of acute gamma irradiation (Mean \pm SEM; $n=3$ ).

\begin{tabular}{ccccc}
\hline & \multicolumn{4}{c}{ Radiation Doses (Gy) } \\
\cline { 2 - 5 } Fatty Acids & Control (0) & $\mathbf{1 0}(\mathbf{G y})$ & $\mathbf{1 5}(\mathbf{G y})$ & $\mathbf{2 0}(\mathbf{G y})$ \\
\hline C12:0 & $1.17 \pm 0.06$ & $2.02 \pm 0.11$ & $1.04 \pm 0.04$ & $1.15 \pm 0.05$ \\
C14:0 & $18.61 \pm 1.02^{\mathrm{ab}}$ & $21.48 \pm 1.18^{\mathrm{a}}$ & $16.49 \pm 0.91^{\mathrm{b}}$ & $15.84 \pm 0.87^{\mathrm{b}}$ \\
C14:1 & $0.67 \pm 0.04$ & $0.47 \pm 0.03$ & $0.41 \pm 0.02$ & $0.46 \pm 0.03$ \\
C15:0 & $3.46 \pm 0.19$ & $3.00 \pm 0.16$ & $2.79 \pm 0.15$ & $2.28 \pm 0.13$ \\
C15:1 & $7.72 \pm 0.42$ & $7.29 \pm 0.40$ & $6.25 \pm 0.34$ & $4.66 \pm 0.26$ \\
C16:0 & $23.90 \pm 1.31$ & $23.34 \pm 1.28$ & $24.76 \pm 1.36$ & $24.46 \pm 1.34$ \\
C16:1 & $1.76 \pm 0.10$ & $2.30 \pm 0.13$ & $2.09 \pm 0.11$ & $2.03 \pm 0.11$ \\
C17:0 & $0.66 \pm 0.04$ & $0.68 \pm 0.04$ & $0.70 \pm 0.04$ & $0.64 \pm 0.04$ \\
C17:1 & $0.55 \pm 0.03$ & $0.47 \pm 0.03$ & $0.50 \pm 0.03$ & $0.66 \pm 0.04$ \\
C18:0 & $6.36 \pm 0.35$ & $5.16 \pm 0.28$ & $4.46 \pm 0.25$ & $4.90 \pm 0.27$ \\
C18:1n-9 & $10.65 \pm 0.59$ & $10.77 \pm 0.59$ & $12.20 \pm 0.67$ & $10.60 \pm 0.58$ \\
C18:2n-6 & $16.73 \pm 0.92$ & $14.06 \pm 0.77$ & $18.06 \pm 0.99$ & $17.54 \pm 0.96$ \\
C18:3n-3 & $18.10 \pm 0.99^{\mathrm{b}}$ & $19.29 \pm 1.06^{\mathrm{b}}$ & $20.58 \pm 1.13^{\text {ab }}$ & $25.10 \pm 1.38^{\mathrm{a}}$ \\
${ }^{2}$ Total monounsaturated fatty acid & $19.59 \pm 1.08$ & $19.00 \pm 1.04$ & $19.36 \pm 1.06$ & $16.39 \pm 0.90$ \\
${ }^{3}$ Total polyunsaturated fatty acid & $34.82 \pm 1.91^{\mathrm{b}}$ & $33.36 \pm 1.83^{\mathrm{b}}$ & $38.64 \pm 2.12^{\mathrm{ab}}$ & $42.65 \pm 2.34^{\mathrm{a}}$ \\
${ }^{4}$ Total n-3 PUFA & $18.10 \pm 0.99^{\mathrm{b}}$ & $19.29 \pm 1.06^{\mathrm{b}}$ & $20.58 \pm 1.13^{\mathrm{ab}}$ & $25.10 \pm 1.38^{\mathrm{a}}$ \\
${ }^{5}$ Total n-6 PUFA & $16.73 \pm 0.92^{\mathrm{b}}$ & $14.06 \pm 0.77$ & $18.06 \pm 0.99$ & $17.54 \pm 0.96$ \\
\hline
\end{tabular}

${ }^{1}$ Total saturated fatty acid $=$ sum of $\mathrm{C} 12: 0+\mathrm{C} 14: 0+\mathrm{C} 15: 0+\mathrm{C} 16: 0+\mathrm{C} 17: 0+\mathrm{C} 18: 0 ;{ }^{2}$ Total monounsaturated fatty acid $=$ sum of $\mathrm{C} 14: 1+\mathrm{C} 15: 1+\mathrm{C} 16: 1+\mathrm{C} 17: 1+\mathrm{C} 18: 1 \mathrm{n}-9 ;{ }^{3}$ Total polyunsaturated fatty acid $=\mathrm{C} 18: 2 \mathrm{n}-6+\mathrm{C} 18: 3 \mathrm{n}-3 ;{ }^{4}$ Total n-6PUFA $=$ sum of C18:2n- $6 ;{ }^{5}$ Total n-3PUFA $=$ sum of $\mathrm{C} 18: 3 \mathrm{n}-3$; ${ }^{\mathrm{a}, \mathrm{b}, \mathrm{ab}}$ Means within rows with different superscript are significantly different at $p<0.05$.

\subsection{Antioxidant Activity (DPPH, FRAP and ABTS Scavenging)}

Curcuma species plants have received much attention, since they produce many beneficial compounds that are useful in the food industry as herbs, flavoring and in the medical industries as an antioxidant and antimicrobial agents. The antioxidant activities of extracts obtained from C. alismatifolia leaves under different gamma irradiation levels in the reactions with DPPH, FRAP, and ABTS assay, illustrated in Figures 2-4, respectively. The antioxidant activities of the extracts generally as the irradiation dose increased and this stimulation reached to its maximum at a dose level of $20 \mathrm{~Gy}$. The $\mathrm{IC}_{50}$ value of the treated and standard leaf extracts presented in Table 5 . Radiation induced oxidative injury by speeding up free radical production in living systems. Radiation stimulates damage to DNA, cell membrane and protein structure (Battino et al.) [24]. The initial damage induced by ionizing radiation is altered in enzymatic repair processes [25]. Several studies showed that the $C$. alismatifolia leaves have antioxidant activities [26,27]. Other leaves from Curcuma spices such as Curcuma zanthorrhiza and Curcuma longa also showed strong antioxidant activities $[28,29]$. It was previously shown that gamma irradiation significantly influenced the cell metabolism and protein synthesis in plant meristem cells [30]. Lee et al. [31] reported an increase in total phenols and total flavonoids in irradiated plants. Such increase in total flavonoids and phenols can 
be due to the degradation of larger phenolic compounds into smaller compounds or release of phenolic compounds from glycosidic components of irradiated leaves as explained by Harrison and Were [17]. Vegetative traits and flowering development showed significant changes, when gamma irradiation at different doses applied for C. alismatifolia var. Sweet Pink [32]. The previous study by Quiles et al. [33] indicted that the best-known antioxidant mechanism of curcuma and its components is their capacity to eliminate reactive oxygen species, such as hydroxyl radical, superoxide radical, singlet oxygen, and NO. They results showed the other points of view regarding the antioxidant mechanism of curcuma extract by protection of the endogenous antioxidants from oxidative damage. In irradiated plants, the leaf length, leaf width, inflorescence length, the number of true flowers, the number of pink bracts, number of shoots, and plant height, decreased significantly $(p<0.05)$ as the radiation dose increased.

Figure 2. Effect of gamma irradiation on the free radical scavenging activity of methanolic extracts and standards at different concentrations. Values are means \pm SE. Each value represents the mean of three replications. * Significance different from Control group at the same concentration. Significance was determined at $p<0.05$.

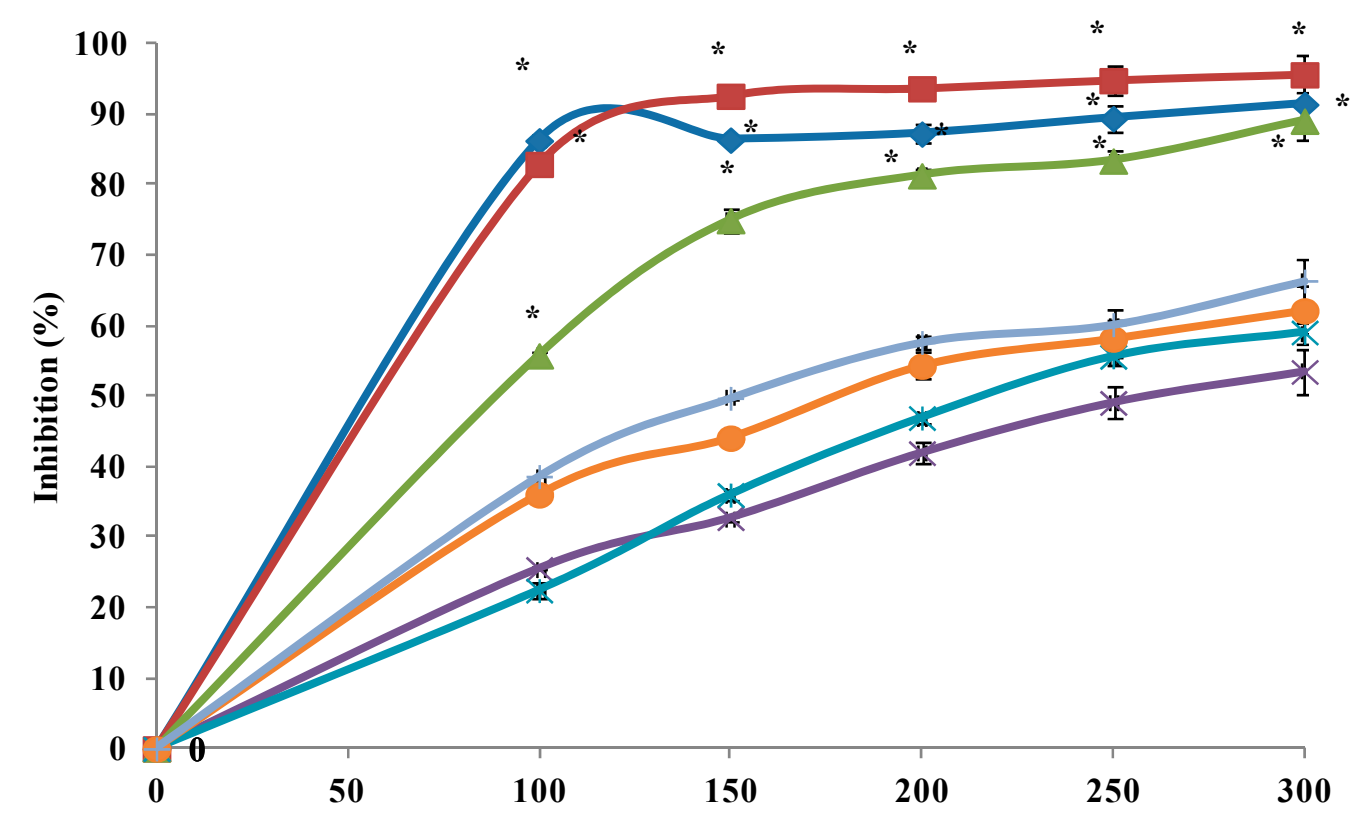

Concentration (ug/ml)

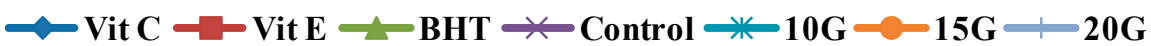


Figure 3. Effect of gamma irradiation on the ferric reduction antioxidant power activity of methanolic extracts and standards at different concentrations. Values are means \pm SE. Each value represents the mean of three replications. * Significance different from Control group at the same concentration. Significance was determined at $p<0.05$.

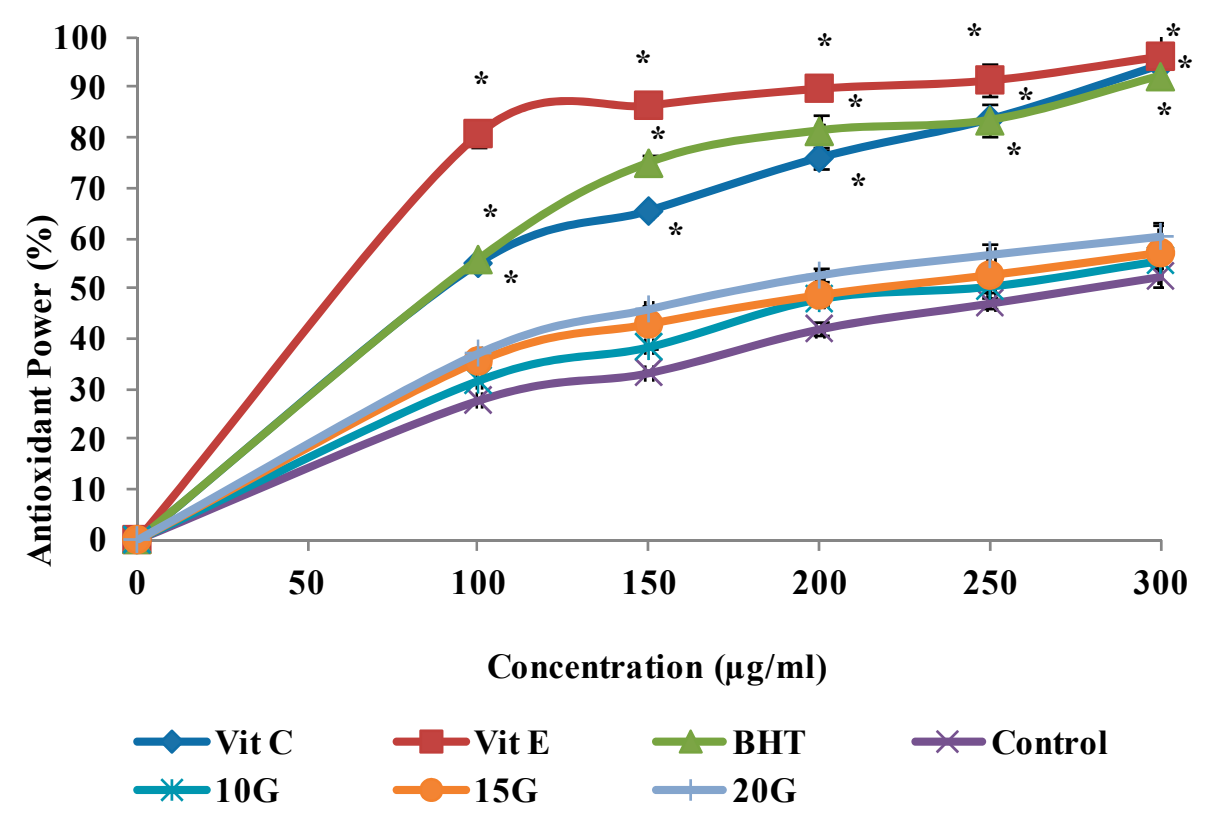

Figure 4. Effect of gamma irradiation on the ABTS radical scavenging activities of methanolic extracts and positive control at different concentrations. Values are means $\pm \mathrm{SE}$. Each value represents the mean of three replications. * Significance different from Control group at the same concentration. Significance was determined at $p<0.05$.

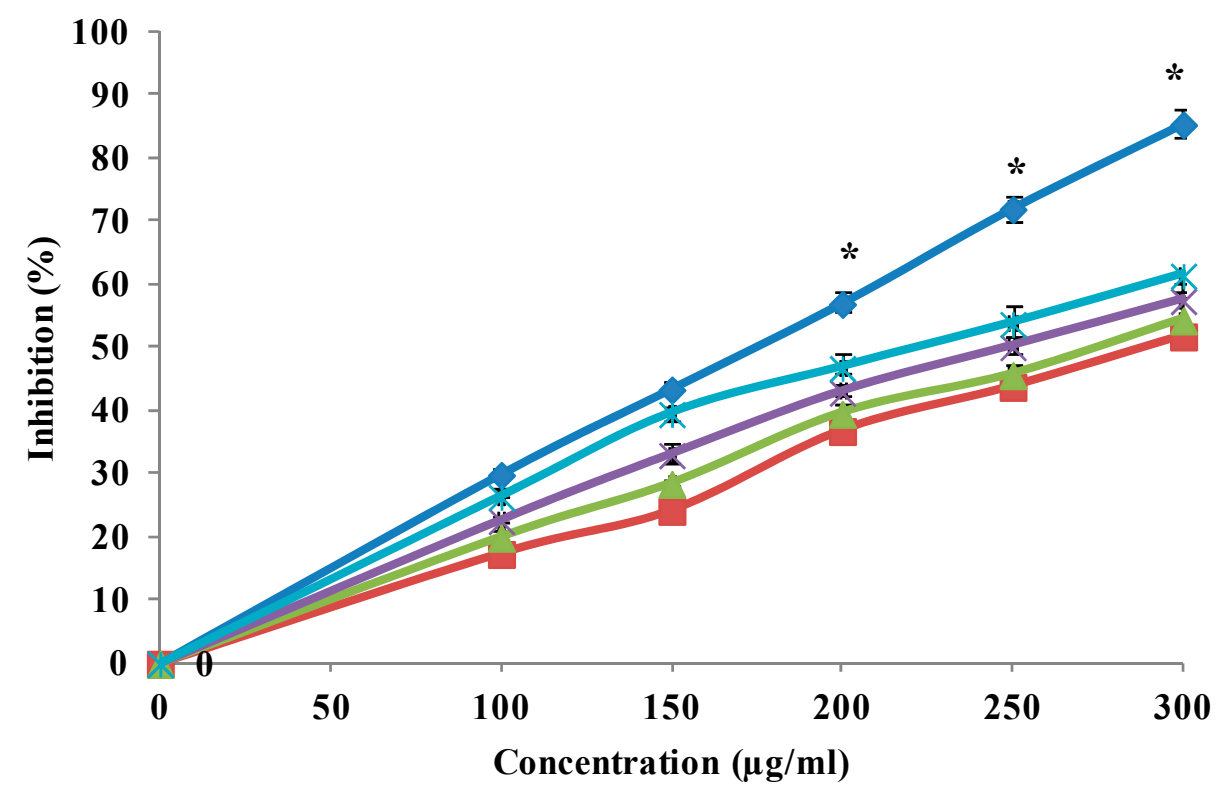

$\leadsto$ Trolox $\leftarrow$ Control $\leftarrow$ 10G $\leftarrow 15 \mathrm{G} \leftarrow 20 \mathrm{G}$ 
Table 5. The $\mathrm{IC}_{50}$ values of extracts and standards in DPPH, FRAP and ABTS scavenging activities (Mean $\pm \mathrm{SEM} ; n=3$ ).

\begin{tabular}{cccc}
\hline & \multicolumn{3}{c}{$\mathbf{I C}_{\mathbf{5 0}}(\boldsymbol{\mu g} / \mathbf{m L})$} \\
\cline { 2 - 4 } Samples & Free Radical Scavenging Activity & Total Antioxidant Activity $^{\mathrm{ABTS} \text { Scavenging Activity }}$ \\
\hline Control & $260.7 \pm 1.29^{\mathrm{a}}$ & $278.1 \pm 1.42^{\mathrm{a}}$ & $288.1 \pm 1.35^{\mathrm{a}}$ \\
$10(\mathrm{~Gy}) 3$ & $218.5 \pm 0.72^{\mathrm{b}}$ & $244.8 \pm 1.56^{\mathrm{b}}$ & $275.8 \pm 0.96^{\mathrm{b}}$ \\
$15(\mathrm{~Gy})$ & $179.3 \pm 1.03^{\mathrm{c}}$ & $218.4 \pm 2.05^{\mathrm{c}}$ & $248.9 \pm 1.12^{\mathrm{c}}$ \\
$20(\mathrm{~Gy})$ & $152.6 \pm 0.85^{\mathrm{d}}$ & $180.7 \pm 1.66^{\mathrm{d}}$ & $225.2 \pm 1.25^{\mathrm{d}}$ \\
Vitamin C & $58.1 \pm 1.47^{\mathrm{f}}$ & $90.9 \pm 2.11^{\mathrm{e}}$ & $\mathrm{ND}$ \\
Vitamin E & $60.3 \pm 3.04^{\mathrm{f}}$ & $61.88 \pm 1.86^{\mathrm{f}}$ & $\mathrm{ND}$ \\
BHT & $89.7 \pm 2.43^{\mathrm{e}}$ & $89.7 \pm 1.37^{\mathrm{e}}$ & $\mathrm{ND}$ \\
Trolox & $\mathrm{ND}$ & $\mathrm{ND}$ & $174.47 \pm 012^{\mathrm{e}}$ \\
\hline
\end{tabular}

ND: not detected; ${ }^{\mathrm{a}, \mathrm{b}, \mathrm{c}, \mathrm{d}, \mathrm{e}, \mathrm{f}}$ Means within columns with different superscript are significantly different at $p<0.05$; DPPH: 1,1-Diphenyl-2-picryl-hydrazyl; FRAP: ferric reduction, antioxidant power; ABTS: 2,2-azino-bis-3ethylbenzothiazoline-6-sulfonic acid.

\section{Experimental}

\subsection{Plant Material}

The plant materials used in this study were the rhizomes of $C$. alismatifolia var. sweet pink (SK 2052/12), measuring of about 2.0-2.5 cm with 4-7 storage root. Rhizomes were provided from a Curcuma nursery (Ubonrat) in Doisaket District, Chiang Mai 50220, Thailand.

\subsection{Planting Media and Preparation of Rhizomes for Acute Gamma Irradiation}

The non-irradiatedrhizomes were treated with a fungicide (Benlate ${ }^{\circledR}$, DuPont Co., Johnston, IA, USA) before planting in a mixture of topsoil: cocopeat: rice husk at the ratio of 1:2:1. Four rhizomes planted per $25 \mathrm{~cm}$ pot. Twenty days after planting, the rhizomes in the sprouting bud stage are dug out from the soil, washed with tap water, dried at room temperature, and wrapped in an aluminum foil $(15 \times 15) \mathrm{cm}^{2}$.

\subsection{Irradiation Treatment}

Irradiation of the rhizomes was conducted in the Faculty of Science and Technology, University Kebangsaan Malaysia (UKM) using a Gamma cell 220 Excel Irradiator (MDS Nordion, Ottawa, ON, Canada). The source of gamma rays was Cobalt $60\left({ }^{60} \mathrm{Co}\right)$. Prepared rhizomes in sprouting bud stage were acutely irradiated at dose levels of $10,15,20 \mathrm{~Gy}$ at room temperature $\left(25 \pm 1{ }^{\circ} \mathrm{C}\right)$. Twenty rhizomes irradiated at each dose level and 20 rhizomes were considered as control. The irradiated rhizomes were planted in $25 \mathrm{~cm}$ pots containing growth media consisting of topsoil:cocopeat:rice husk at the ratio of 1:2:1. The experiment was conducted in Greenhouse No. 1, Field 2, Faculty of Agriculture, Universiti Putra Malaysia (UPM), Malaysia. The experiment was designed as randomized complete block design (RCBD) with five blocks and four replications. The pots were watered manually to saturation once every 2 days, starting after planting of the bulbs. Ovide (Malathion ${ }^{\circledR} 50 \%$, Shanghai AgroChina Chemical Co., Ltd., Shanghai, China) and Benomyl (Benlate ${ }^{\circledR} 50 \%$,Wilmington, $\mathrm{NC}$, USA), were sprayed weekly to prevent the incidence of unwanted pests and diseases. The soil was fertilized with a NPK (15-15-15) once a month at the rate of 5 g per pot [34]. The plants were grown in 
greenhouse for three months (from April to July), and the leaves of treated and non-treated individuals were harvested before flowering starts. The leaf of treated and non-treated samples were freeze-dried, ground to a powder using mortar and pestle and were kept in $-80^{\circ} \mathrm{C}$ for further experiments.

\subsection{Extract Preparation}

The leaf extraction procedure was followed according to the Crozier et al. [35] using methanol. The freeze-dried leaves ( $2 \mathrm{~g})$ were soaked into a $100 \mathrm{~mL}$ conical using $40 \mathrm{~mL}$ of $80 \%(v / v)$ aqueous methanol with the addition of $10 \mathrm{~mL}$ hydrochloridric acid $(6 \mathrm{M})$. The mixture was then refluxed at $90{ }^{\circ} \mathrm{C}$ for $2 \mathrm{~h}$ and filtrated by No. 1 filter paper (Whatman, Camlab Inc., Cambridge, UK) followed by evaporation of the filtrate using a vacuumed Rotary Evaporator (Rotavapor ${ }^{\circledR}$ R-215, Buchi Inc., Uster, Switzerland). The final extracts were dissolved in HPLC grade methanol for determination of flavonoids and phenols.

\subsection{Total Phenols and Flavonoids Determination}

The total phenols and flavonoids were determined according to Ismail et al. [36]. For total phenol determination, briefly $0.5 \mathrm{~mL}$ of each methanolic extract, $2 \mathrm{~mL}$ of $7.5 \%$ sodium carbonate, and $2.5 \mathrm{~mL}$ Folin-Ciocalteu reagent, were mixed together. The mixture was then vortex and incubated for $90 \mathrm{~min}$ at room temperature. The absorbance was read using a visible spectrophotometer (Novaspec II Visible Spectrophotometer, Pharmacia Biotech, Cambridge, UK) at 765 NM. The total phenol results were expressed as mg gallic acid equivalents (GAE)/g dry weight (DW). For total flavonoid compounds $0.1 \mathrm{~mL}$ of methanolic extracts was added to $0.3 \mathrm{~mL}$ sodium nitrite $(5 \%)$ and incubated for $5 \mathrm{~min}$ at room temperature, then $0.3 \mathrm{~mL} 10 \%(w / v) \mathrm{AlCl}_{3}$ and $2 \mathrm{~mL} 1 \mathrm{~N} \mathrm{NaOH}$ was added and the total volume was made up to $5 \mathrm{~mL}$ with distilled water. The absorbance was measured at $510 \mathrm{~nm}$ by using visible spectrophotometer at $510 \mathrm{~nm}$. The results were expressed as mg rutin equivalents $/ \mathrm{g} D W$.

\subsection{Evaluation of Phenolic and Flavonoid Compounds}

The phenolic and flavonoid compounds of samples quantitatively measured by reversed-phase high performance liquid chromatography (HPLC) technique based on Crozier et al. [35]. The standards for phenolic compounds were ellagic acid, salicylic acid, gallic acid, catechin, epicatechin, caffeic acid, cinnamic acid, and resorcinol. The standard for flavonoid compounds were naringin, apigenin, rutin, quercetin, and myricetin. The sample extract was injected on an HPLC Agilent-1200 series instrument equipped with an auto sampler and column (Intersil ODS-3 5 um $4.6 \times 150 \mathrm{~mm}$ Gl Science Inc., CA, USA), pump and UV-Vis photodiode array (DAD) detector. Two solvents including acetonitrile and deionized water were used for mobile phase. The $\mathrm{pH}$ of deionized water was adjusted to be at 2.5. The flavonoid compounds were identified at $350 \mathrm{~nm}$ and phenolic and iso-flavonoid compounds were determined at $280 \mathrm{~nm}$.

\subsection{Fatty Acid Profiles}

C. alismatifolia leaves total fatty acids were extracted according to the method of Folch et al. [37] with some modifications by Ebrahimi et al. [38], using chloroforms: methanol 2:1 (v/v) which 
contained butylated hydroxytoluene to prevent the oxidation during fatty acid extraction. Extracted fatty acids Transmethylated to the fatty acid methyl esters (FAME) using $\mathrm{KOH}$ in methanol and boron trifluoride $\left(\mathrm{BF}_{3}\right)$. The FAME were separated using gas liquid chromatography (Agilent $\left.7890 \mathrm{~A}\right)$, using a Supelco SP 2560 capillary column of $100 \mathrm{~m} \times 0.25 \mathrm{~mm}$ ID $\times 0.2 \mu \mathrm{m}$ film thickness (Supelco, Inc., Bellefonte, PA, USA). One microliter was injected into the gas chromatography, equipped with an injector and a flame ionization detector. The nitrogen was the carrier gas at a flow rate of $1.2 \mathrm{~mL} / \mathrm{min}$. The split ratio was 1:20. The temperature of injector was $250{ }^{\circ} \mathrm{C}$ and the detector temperature was $270{ }^{\circ} \mathrm{C}$. The column temperature program started runs at $150{ }^{\circ} \mathrm{C}$, for $2 \mathrm{~min}$, warmed to $158^{\circ} \mathrm{C}$ at $1{ }^{\circ} \mathrm{C} / \mathrm{min}$, held for $28 \mathrm{~min}$, warmed to $220{ }^{\circ} \mathrm{C}$ at $1{ }^{\circ} \mathrm{C} / \mathrm{min}$, and then held for $20 \mathrm{~min}$. A reference standard (C4-C24 methyl esters; Sigma-Aldrich, Inc., St. Louis, MS, USA), was used to determine correction factors for the determination of individual fatty acid composition. The data are expressed as $\mathrm{g} / 100 \mathrm{~g}$ of detecting total fatty acids.

\subsection{Antioxidant Activity}

\subsubsection{DPPH Free Radical Scavenging Activity}

The DPPH of the extracts were determined by Gulcin et al.'s [39] method. The activities of DPPH were expressed as percentage of inhibition and calculated by following equation according to Yen and Chen [39].

$$
\left.\% \text { inhibition of DPPH activity }=\left[\left(\mathrm{A}_{0}-\mathrm{A}_{1}\right) / \mathrm{A}_{0}\right)\right] \times 100 \%
$$

where $A_{0}$ was the absorbance value of the control or blank sample and A1 was the absorbance value of the test sample. A curve of $\%$ inhibition or $\%$ scavenging effect against sample concentrations was plotted and the concentration of the sample required for 50\% inhibition was determined. The value for each of the test sample was shown as the inhibition curve at 50\%. BHT, $\alpha$-tocopherol and vitamin $\mathrm{C}$ were utilized as standard antioxidants.

\subsubsection{Ferric Reducing Antioxidant Power (FRAP)}

The FRAP property of the extracts was determined using a method as described by Yen and Chen [40]. The test was completed in triplicate. BHT, $\alpha$-tocopherol and vitamin $\mathrm{C}$ were utilized as standard antioxidants.

\subsubsection{ABTS Radical Cation-Scavenging}

The ABTS was evaluated by the method of Giao et al. [41]. ABTS was dissolved in water; to a $7 \mathrm{~mm}$ concentration. ABTS radical cation $\left(\mathrm{ABTS}^{\circ+}\right.$ ) was produced by reacting ABTS stock solution with $2.45 \mathrm{mM}$ $\mathrm{K}_{2} \mathrm{~S}_{2} \mathrm{O}_{8}$ and allowing the mixture to stand at room temperature (dark place) overnight before utilization.

\subsection{Statistical Analysis}

All data are presented as means $( \pm$ SEM $)$ of at least three replicates $(n=3)$. The total phenolic and flavonoid contents, fatty acid, DPPH, and FRAP were analyzed using analysis of variance (ANOVA) with the Statistical Analysis System (SAS) Version 9.1 (SAS Institute, Cary, NC, USA). Significant 
differences among means from triplicate analyses $(p<0.05)$ were determined by Duncan's Multiple Range Test. The level of significance was set at $p<0.05$ for all statistical tests.

\section{Conclusions}

Gamma irradiation has been generally used in biology and medicine regarding biological activity effects. In plant breeding projects, mutagenic treatments with low negative physiological impacts and suitable genetic effects are desirable. Consequently, we utilized more powerful and effective doses of gamma irradiation $(10,15$, and $20 \mathrm{~Gy})$ of which, especially, the 20 Gy dose was viable to influence morphological attributes of examining $C$. alismatifolia variety. In addition, results from previous studies, showed higher percentage of plant growth mutation and getting wanted mutants at 20 Gy of acute gamma irradiation. In addition, from this experiment, it is inferred that radiation dose up to 20 Gy can enhance the quality and amount of bioactive compounds, including phenolic and flavonoid, in addition to the improvement of scavenging activity in C. alismatifolia var. Sweet pink leaves.

\section{Acknowledgments}

This work was funded by the Fundamental Research Grant Scheme (FRGS) under the Ministry of Higher Education in Malaysia.

\section{Author Contributions}

All authors contributed extensively to the work presented in this paper. Ehsan Karimi and Sima Taheri designed the experiments and prepared the manuscript. Sima Taheri, Ehsan Karimi, Mahdi Ebrahimi, and Ehsan Oskoueian performed the experiments. Thohirah Lee Abdullah supervised the experiments and edited the manuscript.

\section{Conflicts of Interest}

The authors declare no conflict of interest.

\section{References}

1. Finley, J.W. Bioactive compounds and designer plant foods: The need for clear guidelines to evaluate potential benefits to human health. Chronica. Hotric. 2005, 45, 6-11.

2. Karimi, E.; Jaafar, H.Z.E.; Ahmad, S. Antifungal, anti-inflammatory and cytotoxicity activities of three varieties of Labisiapumilabenth: From microwave obtained extracts. BMC Complement. Altern. Med. 2013, 13, 1-10.

3. Oskoueian, E.; Abdullah, N.; Hendra, R.; Karimi, E. Bioactive compounds, antioxidant, xanthine oxidase inhibitory, tyrosinase inhibitory and anti-inflammatory activities of selected agro-industrial by-products. Int. J. Mol. Sci. 2011, 12, 8610-8625.

4. Pandey, K.B.; Rizvi, S.I. Plant polyphenols as dietary antioxidants in human health and disease. Oxid. Med. Cell. Longev. 2009, 2, 270-278.

5. Namuli, A.; Abdullah, N.; Sieo; C.; Zuhainis, S.; Oskoueian, E. Phytochemical compounds and antibacterial activity of Jatrophacurcas Linn extracts. J. Med. Plants Res. 2011, 5, 3982-3990. 
6. Hendra, R.; Ahmad, S.; Sukari, A.; Shukor, M.Y.; Oskoueian, E. Flavonoid analyses and antimicrobial activity of various parts of Phaleria macrocarpa (Scheff.) boerl Fruit. Int. J. Mol. Sci. 2011, 12, 3422-3431.

7. Argolo, A.C.C.; Sant-Ana, A.E.G.; Pletsch, M.; Coelho, L.C.B.B. Antioxidant activity of leaf extracts from Bauhinia monandra. Bioresour. Technol. 2004, 95, 229-233.

8. Tepe, B.; Sokmen, M.; Akpulat, H.A.; Sokmen, A. In vitro antioxidant activities of the methanol extracts of four Helichrysum species from Turkey. Food Chem. 2005, 90, 685-689.

9. Marinova, D.; Ribarova, F.; Atanassova, M. Total phenolics and total flavonoids in Bulgarian fruits and vegetables. J. Univ. Chem. Technol. Metall. 2005, 40, 255-260.

10. Pusglove, J.W. Tropical Crops: Dicotyledons 1, Dicotyledons 2; Longmans: London, UK, 1968.

11. Apavatjrut, P.; Anuntalabhochai, S.; Sirirugsa, P.; Alisi, C. Molecular markers in the identification of some early flowering Curcuma L. (Zingiberaceae) species. Ann. Bot. Lond. 1999, 84, 529-534.

12. Lewis, M.E. Should we be concerned about herbal remedies. J. Ethnopharmacol. 2001, 75, 141-164.

13. Charbaji, T.; Nabulsi, I. Effect of low doses of gamma irradiation on in vitro growth of grapevine. Plant Cell Tissue Organ Cult. 1999, 57, 129-132.

14. Chakravarty, B.; Sen, S. Enhancement of regeneration potential and variability by $\gamma$-irradiationin cultured cells of Scillaindica. Biol. Plant 2001, 44, 189-193.

15. Cantos, E.; Garcia-Viguera, C.; Pascal-Teresa, S.D.; Tomas-Barberan, F. Effect of postharvest ultraviolet irradiation on resveratrol and other phenolics of cv. Napolean table grapes. J. Agric. Food Chem. 2000, 48, 4606-4612.

16. Variyar, P.S.; Bandyopadhyay, C.; Thomas, P. Effect of c-irradiation on the phenolic acid of some Indian spices. Int. J. Food Sci. Technol. 1998, 33, 533-537.

17. Harrison, K.; Were, L.M. Effect of gamma irradiation on total phenolic content yield and antioxidant capacity of Almond skin extracts. Food Chem. 2007, 102, 932-937.

18. Guttman, A.; Khandurina, J.; Budworth, P.; Xu, W.; Hou, Y.M.; Wang, X. Analysis of combinatorial natural products by HPLC and CE. LC-GC N. Am. 2004, 22, 58-67.

19. Lewis, N.F.; Madhavesh, D.A.; Qumta, U.S. Role of carotenoid pigments on radio-resistant Micococci. Can. J. Microbiol. 1974, 20, 455-459.

20. Work, E. Amino acids of walls of Micrococcus radiodurans. Nature 1964, 201, 1107-1109.

21. Lewis, N.F. Studies on the Lipids and Fatty Acid Composition of Micrococcus Radiodurans. M.S. Thesis, Oregon State University, Corvallis, OR, USA, 1968.

22. Byun, M.W.; Kang, I.J.; Kwon, J.H.; Hayashi, Y.; Mori, T. Physicochemical properties of soybean oil extracted from $\gamma$-irradiated soybeans. Radiat. Phys. Chem. 1996, 47, 301-304.

23. Štajner, D.; Milošević, M.; Popović, B.M. Irradiation effects on phenolic content, lipid and protein oxidation and scavenger ability of soybean seeds. Int. J. Mol. Sci. 2007, 8, 618-627.

24. Battino, M.; Ferri, E.; Gattavecchia, E.; Breccia, A.; Genova, M.L.; Littarru, G.P.; Lenaz, G. Mitochondrial respiratory chain features after gamma-irradiation. Free Radic. Res. 1997, 26, 431-438.

25. Alikamanoglu, S.; Yaycli, O.; Atak, C.; Rzakoulieva, A. Effect of magnetic field and gamma radiation on Paulowiniatomentosa tissue culture. Biotechnol. Biotechnol. Equip. 2007, 21, 129-134.

26. Akter, R.; Hasan, S.R.; Siddiqua, S.A.; Majumder, M.M.; Hossain, M.M.; Alam, M.A.; Ghani, A. Evaluation of analgesic and antioxidant potential of the leaves of Curcuma alismatifolia Gagnep. Stamford J. Pharm. Sci. 2008, 1, 3-9. 
27. Akter, R.; Hasan, S.M.; Hossain, M.M.; Jamila, M.; Chowdhury, S.S.; Mazumder, M.E.H.; Rahman, S. Antidiarrhoeal and antioxidant properties of Curcuma alismatifolia leaves. Aust. J. Basic Appl. Sci. 2010, 4, 450.

28. Chan, E.W.C.; Lim, Y.Y.; Wong, L.F.; Lianto, F.S.; Wong, S.K.; Lim, K.K.; Lim, T.Y. Antioxidant and tyrosinase inhibition properties of leaves and rhizomes of ginger species. Food Chem. 2008, 109, 477-483.

29. Chan, E.W.C.; Lim, Y.Y.; Wong, S.K.; Lim, K.K.; Tan, S.P.; Lianto, F.S.; Yong, M.Y. Effects of different drying methods on the antioxidant properties of leaves and tea of ginger species. Food Chem. 2009, 113, 166-172.

30. Casarett, A.P. Radiation Chemistry; Prentice Hall: Englewood Cliffs, NJ, USA, 1968.

31. Lee, J.W.; Kim, J.K.; Srinivasan, P.; Choi, J.; Kim, J.H.; Han, S.B.; Kim, D.J.; Byun, M.W. Effect of gamma irradiation on microbial analysis, antioxidant activity, sugar content and color of ready-to-use tamarind juice during storage. LWT-Food Sci. Technol. 2009, 42, 101-105.

32. Taheri, S.; Abdullah, T.L.; Ahmad, Z.; Abdullah, N.A.P. Effect of acute gamma irradiation on Curcuma alismatifolia varieties and detection of DNA polymorphism through SSR Marker. Biol. Med. Res. Int. 2014, 2014, 1-18.

33. Quiles, J.L.; Mesa, M.D.; Ramírez-Tortosa, C.L.; Aguilera, C.M.; Battino, M.; Gil, A.; Ramírez-Tortosa, M.C. Curcuma longa extract supplementation reduces oxidative stress and attenuates aortic fatty streak development in rabbits. Arterioscler. Thromb. Vasc. Biol. 2002, 22, 1225-1231.

34. Bunya-atichart, K.; Saichol, K.; van Doorn, W.G. Postharvest physiology of Curcuma alismatifolia flowers. Postharvest Biol. Technol. 2004, 34, 219-226.

35. Crozier, A.; Jensen, E.; Lean, M.E.J.; McDonald, M.S. Quantitative analysis of flavonoids by reversed-phase high-performance liquid chromatography. J. Chromatogr. 1997, 761, 315-321.

36. Ismail, H.I.; Chan, K.W.; Mariod, A.A.; Ismail, M. Phenolic content and antioxidant activity of cantaloupe (cucumismelo) methanolic extracts. Food Chem. 2010, 119, 643-647.

37. Folch, J.; Lees, M.; Sloane Stanley, G.H. A simple method for the isolation and purification of total lipids from animal tissues. J. Biol. Chem. 1975, 1, 497-509.

38. Ebrahimi, M.; Rajion, M.A.; Goh, Y.M.; Sazili, A.Q.; Schonewille, J.T. Effect of Linseed Oil Dietary Supplementation on Fatty Acid Composition and Gene Expression in Adipose Tissue of Growing Goats. Biomed. Res. Int. 2013, 2013, 1-11.

39. Gulcin, I.; Gungor Sat, I.; Beydemir, S.; Elmastas, M.; IrfanKufrevioglu, O. Comparison of antioxidant activity of clove (Eugenia caryophylata Thunb) buds and lavender (Lavandulastoechas L.). Food Chem. 2004, 87, 393-400.

40. Yen, G.C.; Chen, H.Y. Antioxidant activity of various tea extracts in relation to their antimutagenicity. J. Agric. Food Chem. 1995, 43, 27-32.

41. Giao, M.S.; Gonzalez-Sanjose, M.L.; Rivero-Perez, M.D.; Pereira, C.I.; Pintado, M.E.; Malcata, F.X. Infusions of Portuguese medicinal plants: Dependence of final antioxidant capacity and phenolic content on extraction features. J. Sci. Food Agric. 2007, 87, 2638-2647.

(C) 2014 by the authors; licensee MDPI, Basel, Switzerland. This article is an open access article distributed under the terms and conditions of the Creative Commons Attribution license (http://creativecommons.org/licenses/by/3.0/). 